\title{
Desenvolvimento e Avaliação de Técnicas para Pulsação da Alimentação de Arame em Soldagem a Arco
}

\author{
Vinícius Lemes Jorge ${ }^{1}$, César Henrique Alves Santos ${ }^{1}$, Fernando Matos Scotti ${ }^{1}$, Thiago Resende Larquer ${ }^{1,2}$, \\ Carolina Pimenta Mota2 ${ }^{2}$ Ruham Pablo Reis ${ }^{1}$, Américo Scotti ${ }^{1,3}$ \\ 1 Universidade Federal de Uberlândia - UFU, Centro para Pesquisa e Desenvolvimento de Processos de Soldagem - Laprosolda, \\ Uberlândia, MG, Brasil. \\ 2 Instituto Federal de Educação, Ciência e Tecnologia do Triângulo Mineiro - IFTM, Patos de Minas, MG, Brasil. \\ 3 University West, Department of Engineering Science, Production Technology West, Division of Welding Technology, \\ Trollhättan, Sweden.
}

Recebido: 22 Maio, 2018

Aceito: 20 Ago., 2018

E-mails: viniciuslemesj@hotmail.com (VLJ), cesarmct@gmail.com (CHAS), fernandomscotti@gmail.com (FMS), thiagolarquer@gmail.com (TRL), cpimentamota@gmail.com (CPM), ruhamreis@ufu.br (RPR), ascotti@ufu.br, americo.scotti@hv.se (AS)
Resumo: Uma das novas abordagens em soldagem é a aplicação de técnicas de alimentação pulsada do arame de adição para TIG e MIG/MAG. Entretanto, tais técnicas necessitam de alimentadores de arame e/ou tochas específicos, o que acaba limitando sua implementação pelo custo destes equipamentos. Assim, o presente trabalho tem como objetivo introduzir e avaliar de forma exploratória técnicas para pulsar a alimentação do arame aplicadas de forma independentemente de alimentadores e/ou tochas especiais. São apresentadas uma técnica com acionamento eletromecânico e outra com eletromagnético. Foram avaliados os efeitos da amplitude e frequência da alimentação pulsada sobre a formação de cordões de solda sobre chapa e sobre os sinais elétricos correspondentes. Para TIG, percebeu-se que a pulsação da alimentação tem potencial para modificar o cordão e tornar mais regular a transferência de material para a poça. Já para MIG/MAG, verificou-se que a pulsação da alimentação pode interferir no processo, sendo capaz de modificar uma transferência metálica globular irregular para regular, reduzindo a corrente média e afetando a formação do cordão. A pulsação da alimentação do arame, mesmo de forma independente de alimentadores e/ou tochas especiais, é então capaz de interferir nos processos, abrindo um campo de desenvolvimento de tecnologias de soldagem derivativas.

Palavras-chave: Pulsação da alimentação de arame; TIG; MIG/MAG.

\section{Development and Evaluation of Wire Feeding Pulsing Techniques for Arc Welding}

Abstract: Applying pulsed wire feeding techniques is one of the new approaches for welding, such as for GTAW and GMAW. However, these techniques invariably require specific feeders and/or welding torches, limiting its implementation due to the high costs of the equipment. Thus, the current work aims to introduce and exploratorily evaluate techniques to pulse the wire feeding that works independently from the feeder and/or torch. The first technique is electromechanically driven, and the second one based on electromagnetics. The effects of amplitude and frequency of the pulsed feeding were evaluated in terms of weld bead formation over plates and of the corresponding electric signals. For GTAW, the pulsed wire feeding is capable of modifying the weld bead and make the metal transfer from the wire to the pool more regular. For GMAW, it was found that the pulsing of the wire feeding can interfere with the process, being capable of turning an irregular globular metal transfer into a regular one, while decreasing the mean current and affecting the bead formation. Overall, it is concluded that pulsed wire feeding can affect the processes, even when made independently from the feeder and torch, opening a field for development of derivative welding technologies.

Key-words: Pulsed wire feeding; GTAW; GMAW.

\section{Introdução}

Para cada um dos processos tradicionais de soldagem, existem diferentes variações que visam atender a particularidades de cada aplicação, a fim de garantir melhorias na qualidade da solda, maior produtividade ou mesmo possibilitar a execução de determinado procedimento que antes não era possível. Essas variações aplicadas aos processos são classificadas como Processos Derivativos. A grande vantagem dos processos derivativos sobre processos totalmente novos (inovativos) é que se baseiam em uma plataforma já sob a licença Creative Commons Attribution Non-Commerc que permite uso, distribuição e reprodução em qualquer meio, sem restriçôes desde que sem fins comerciais e que o trabalho original seja corretamente citado. 
conhecida e testada, tendo mais aceitabilidade pelo público consumidor. Tais variações acontecem muitas das vezes pelo desenvolvimento de tecnologias capazes de alterar fenômenos ocorrentes nos processos. A forma com que se faz a adição de material em soldagem tem sido, por isto, alvo de inovações nos últimos anos, com o lançamento de sistemas que promovem a pulsação do material de adição, ou seja, seu avanço e retrocesso de forma rápida e cíclica em soldagens manuais ou mecanizadas. A pulsação da alimentação do arame foi provavelmente reportada pela primeira vez por Rudy [1], ainda em 1982, ao descrever sua técnica denominada Dabber TIG, na qual se fazia uma alimentação intermitente de arame de enchimento para a poça de solda fundida. Na opinião dos autores do presente trabalho, a ideia de se pulsar a alimentação do arame surgiu ao se buscar emular a técnica realizada por soldadores do processo TIG, na qual ele tira e coloca a vareta de forma consistente e ponderada durante a execução da solda.

Já existem comercialmente equipamentos baseados no princípio de adição pulsada de material. O TIP TIG ${ }^{\circledR}$, desenvolvido, comercializado e patenteado [2] é baseado num sistema de alimentação de arame que possui um conjunto de motor e mecanismo de quatro barras responsável por promover um efeito vibratório longitudinalmente no conjunto motor e roletes, resultando na pulsação linear do material de adição, aliado a um sistema de aquecimento do arame. Em um relatório de avaliação do $\operatorname{TIPTIG}^{\circledR}$ [3], o autor afirma que o efeito de pulsação se mostra capaz de melhorar a dinâmica da poça de fusão, conferindo maior fluidez e reduzindo risco de inclusões e porosidade, quando comparado ao processo TIG tradicional, além de aumentar velocidade de soldagem e taxa de deposição. O TIGSpeed ${ }^{\circledR}$, da empresa alemã EWM opera de forma semelhante, baseado na patente do TIPTIG $^{\circledR}$. O fabricante destaca que um melhor controle da poça de fusão é possível com o uso do equipamento, alcançando velocidades de soldagem mais altas, menor transferência de calor e maior conforto para o soldador. Dois trabalhos recentes abordam este processo, ao que parece por meio do equipamento TIP TIG ${ }^{\circledR}$. Em um deles, Silwal e Santangelo [4] avaliam o processo de soldagem TIG com arame de adição (quente ou frio), com ou sem pulsação da alimentação. A frequência de pulsação da alimentação utilizada foi de $16 \mathrm{~Hz}$. Os efeitos observados na transferência metálica e na formação do cordão de solda foram mais relacionados à utilização de aquecimento ou não do arame de adição do que ao emprego ou não da alimentação pulsada. Em um outro trabalho [5], ressalta-se que o arame quente pode ser utilizado junto com a pulsação da alimentação para obter depósitos mais uniformes e com potencial aplicação em operações de manufatura aditiva. Como sugere Silva et al. [6], apesar de haver estudos, os fundamentos físicos do comportamento da pulsação da velocidade de alimentação no processo TIG ainda não estão estabelecidos. Em seus estudos, com baixa frequência $(0 \mathrm{a} 2 \mathrm{~Hz}$ ), eles tentaram esclarecer alguns fatos sobre a transferência metálica e gradiente de temperatura na poça. Por exemplo, eles verificaram que a possibilidade de se ter a transferência do arame para a poça dentro da própria poça é uma vantagem para aplicação do processo fora da posição plana.

Já para o caso do processo MIG/MAG, o processo mais conhecido para movimentar linearmente o arame para frente e para traz, não de forma pulsada do ponto de vista clássico da definição, é o $\mathrm{CMT}^{\circledR}$, produzindo pela indústria austríaca Fronius. O CMT utiliza uma tocha especial que permite a reversão periódica do avanço do arame-eletrodo, através de sistema motor para tração do arame-eletrodo. Assim, o CMT utiliza dois conjuntos de motores e roletes tracionadores - um na frente, junto à tocha, que puxa o arame e o recua até cerca de 70 vezes por segundo e outro, localizado no alimentador, que empurra o arame. Ambos são digitalmente controlados sendo que o frontal não possui redutores e possui um servo motor $\mathrm{AC}$ altamente dinâmico [7]. $\mathrm{O}$ avanço permite que o arame toque a poça de fusão (neste instante, a corrente é também reduzida drasticamente), permitindo uma transferência suave da gota para a poça. Na reversão, após um determinado tempo, a gota é destacada (como a corrente é baixa, não há picos de correntes de curtos circuitos, reduzindo-se respingos. Como o arco fica sempre mais curto do que numa soldagem convencional, para uma dada corrente média, a energia calorífica transferida para a peça é muito baixa, justificando o nome Cold Metal Transfer.

No entanto, tais mecanismos para pulsar o arame estão atrelados aos alimentadores em seu interior ou a tochas especiais. Sendo assim, sua utilização exigiria a substituição de sistemas convencionais por equipamentos específicos, o que dificulta, na maioria das vezes, sua aceitação na indústria. Uma proposta seria que o mecanismo de pulsação ficasse de fora do cabeçote alimentador e fosse adaptável a qualquer equipamento. Outra opção seria colocá-lo próximo à tocha, mas não como parte integrante dela, já que tornaria a tocha pesada, dificultando a soldagem manual ou semiautomática.

Existem alguns mecanismos patenteados para pulsar o arame, baseados em diferentes princípios de acionamento [8-10], efetuando a pulsação com uso de um ou mais eletroímãs. De forma comum às três, as 
frequências de pulsação são reguladas pela frequência de aplicação das correntes elétricas nas bobinas dos eletroímãs. No entanto, alterações na amplitude de pulsação não podem ser facilmente realizadas. No invento descrito em [11], a empresa Paton Electroweld Ind utilizou um disco acionando por um motor com eixo de giro paralelo ao eixo longitudinal de uma seção livre e deslizante de conduíte elástico e duas presilhas autoblocantes com alojamento cônico nas extremidades dessa seção que operam alternadamente para permitir a alimentação do arame em pulsos. Em outros inventos da empresa Paton Electroweld Ind [12,13], o movimento de avanço e recuo de uma carcaça que envolve o sistema aciona ou não um segundo mecanismo que traciona o arame de modo a gerar a pulsação da alimentação com avanços e paradas subsequentes. Em todas as patentes comentadas acima, a amplitude e frequência de pulsação do arame são dependentes e não podem ser regulados separadamente.

Gribachev [14] utilizou dois sistemas de embreagens de roda livre (catraca) montados dentro do alimentador para fazer a pulsação da velocidade do arame. Um dos sistemas é conectado na saída do eixo do motor do alimentador de arame em velocidade contínua e o segundo logo à frente deste eixo e assim antes dos roletes tracionadores de arame. Este segundo sistema é utilizado para sobrepor temporariamente maiores velocidades de giro do eixo de comando dos roletes tracionadores de arame e assim de velocidade de alimentação do arame. Dessa forma, a velocidade de alimentação do arame é sempre adiante (sem recuos), mas com avanços intermitentes (pulsos). A amplitude, frequência e velocidade da sobreposição de movimento angular do eixo e assim da velocidade de alimentação do arame são regulados por um mecanismo biela-manivela acionado por um segundo motor.

Apesar da ideia de pulsar a alimentação do arame não ser nova, a eficácia dessa técnica é pouco explorada na literatura científica. Portanto, este trabalho tem como objetivo apresentar e avaliar de forma exploratória a ideia de se pulsar a alimentação do arame com configuração externa ao cabeçote e não utilizando tochas especiais, visando no futuro aplicar este conceito aos processos TIG e MIG/MAG em modalidades de processos derivativos.

\section{Técnicas Propostas}

No esquema apresentado na Figura 1 é mostrada como a abordagem geral de pulsação de alimentação do arame de forma externa aqui apresentada funciona. $O$ arame corre por dentro de um conduíte, sendo impulsionado a uma velocidade constante pelo alimentador de arame, como ilustra o quadro (1) da Figura 1. Como esta velocidade de alimentação é igual, em média, à taxa de fusão do arame (assumindo haver um arco com energia suficiente para igualar a taxa de alimentação com a taxa de fusão do arame), a ponta do arame assume uma distância fixa em relação ao guia na saída. No quadro 2 , um movimento transversal é aplicado em um ponto do conduíte, de tal forma que, ao flexioná-lo, o arame que vem sendo alimentado a uma velocidade constante sofre retração, pois é puxado para traz junto com o conduíte. Assim, o recuo do arame $(R)$ é obtido pela razão geométrica da amplitude de flexão alternada $(\mathrm{H})$ e do comprimento livre do conduíte (L) que fica sob ação da flexão transversal. Com o retorno do conduíte para a posição de referência (quadro 3), a ponta do arame volta à posição original, uma vez que a taxa de fusão do arame continua igual à sua velocidade de alimentação. Como o arame fica livre para deslizar dentro do conduíte, fisicamente o que ocorre é um aumento momentâneo do comprimento da trajetória que o arame tem de percorrer. Se a velocidade de alimentação provida pelo alimentador é fixa, tem-se neste momento menos arame saindo do pulsador, ou seja, chegando na posição do arco/poça.

Existem várias outras técnicas de fazer esta flexão de forma transversal, patenteadas ou não. 0 efeito da flexão pode também ser conseguido, por esforços longitudinais no sentido contrário ao da alimentação ou esforços transversais. Pelos esforços longitudinais, o arame é flambado (regime elástico) ao invés de flexionado periodicamente. Essa flambagem pode ser conseguida por efeito eletromagnético. Ou por ação da inversão de rotação de um rolete impulsionador, como se faz no caso da tecnologia Cold Metal Transfer (CMT) empregada na soldagem MIG/MAG. Mas no caso da CMT, se utiliza uma abordagem de "pulmão" passivo, o qual acomoda as diferenças entre a velocidade de avanço do arame, provida pelo alimentador, e a velocidade de recuo, provida pelo rolete impulsionador dentro da respectiva tocha proprietária do processo, acomodando a flambagem e evitando que $o$ arame possa se dobrar plasticamente (seja amassado).

No caso das 2 técnicas aqui introduzidas, a pulsação da alimentação é conseguida pela flexão transversal alternada do conduíte e, consequentemente, do arame. Assim, o pulsador poderia ser caracterizado como um "pulmão" ativo, ou seja, ocorre uma imposição de movimento de flexão sobre o arame, e não de flambagem, que se executada dentro de certos limites não o dobra plasticamente (permanentemente). A primeira técnica usada neste 
trabalho se dá por ação eletromecânica e a segunda por ação eletromagnética. Na Figura 2 são apresentados os dois dispositivos para acionar a flexão para se conseguir pulsar um arame maciço impulsionado por um alimentador comercial de arame frio. Detalhes de funcionamento de cada dispositivo são apresentados na seção seguinte.
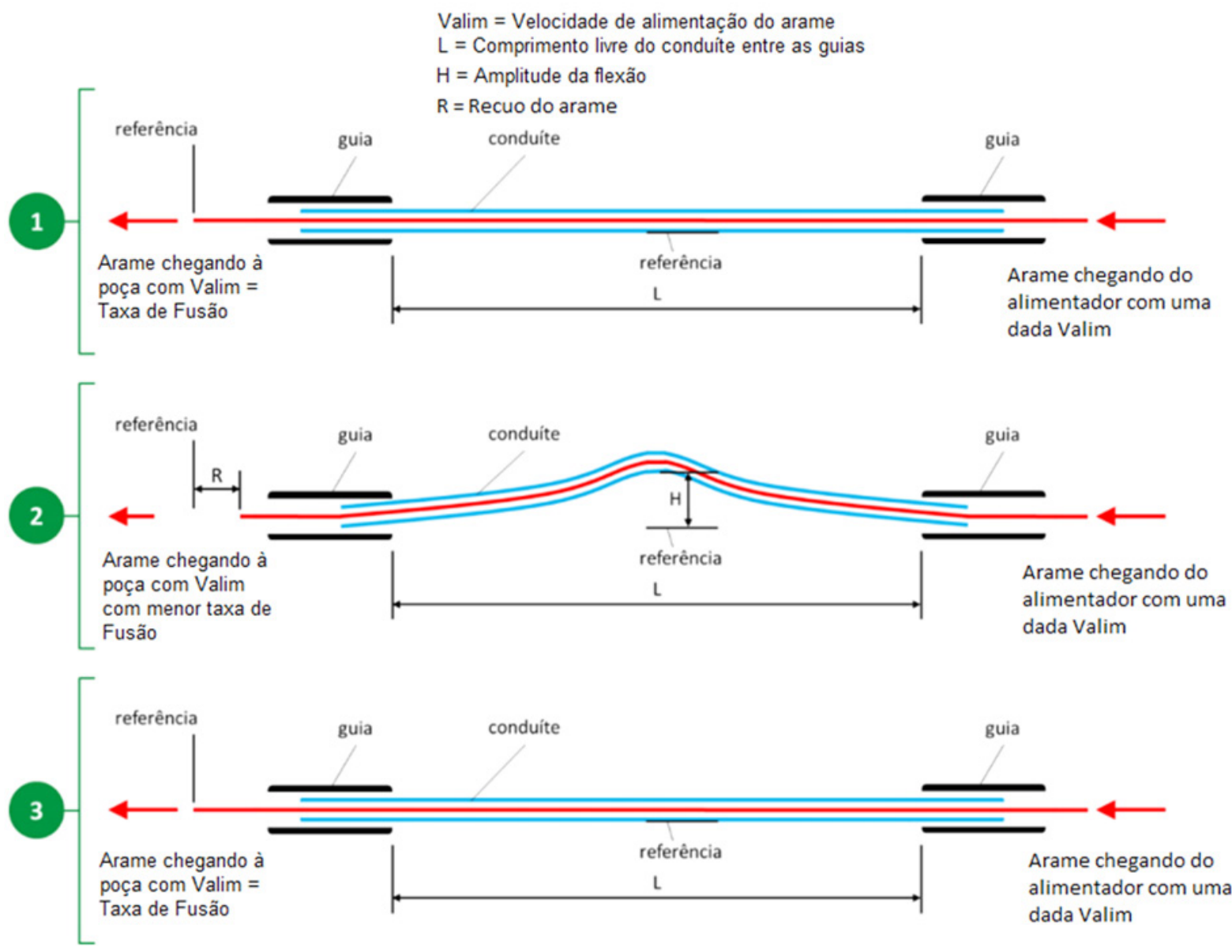

Figura 1. Esquema de funcionamento da abordagem para pulsação da alimentação do arame. Adaptado de Santos [15].
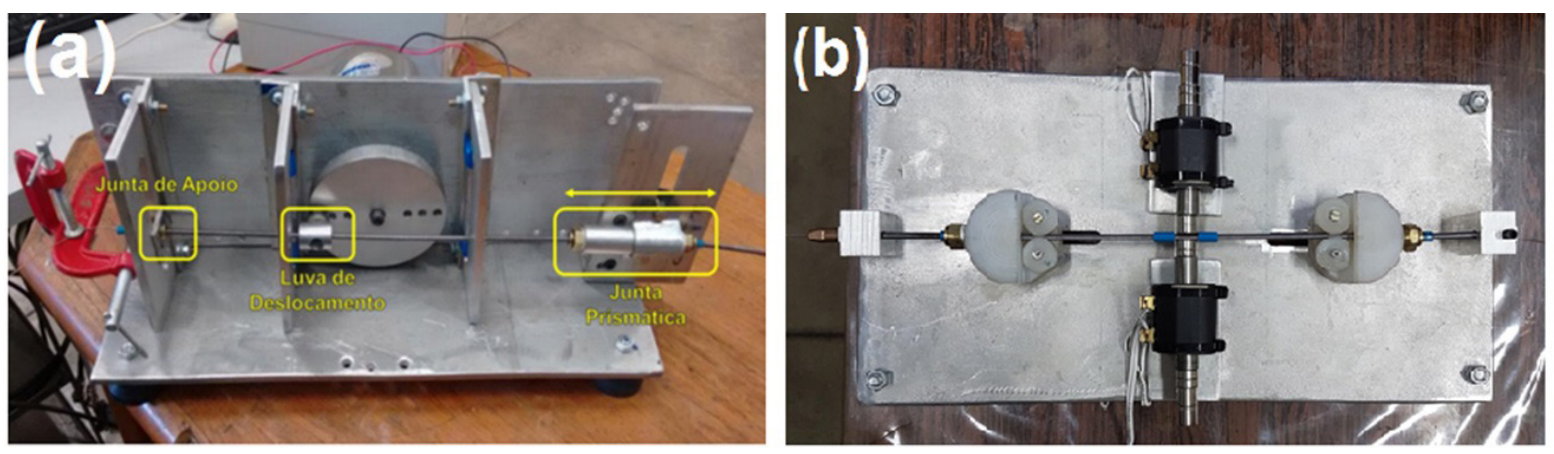

Figura 2. Dispositivos para pulsação da alimentação de arame: (a) por ação eletromecânica; (b) por ação eletromagnética. 


\subsection{Dispositivo com acionamento eletromecânico}

\subsubsection{Funcionamento}

Neste dispositivo, um disco de alumínio é fixado ao eixo de um motor, responsável pelo seu movimento rotativo. $\mathrm{O}$ disco possui seis furos colineares ao seu raio, divididos em grupos de três em cada hemisfério do disco. Estes furos têm como função permitir que se coloquem pinos (ressaltos) para mudar a amplitude de flexão do comprimento livre do conduíte (variável H da Figura 1), mudando a distância da guia do conduíte ao centro do eixo do disco. Esta característica é uma desvantagem desta técnica por impedir a mudança da amplitude de flexão de forma remota.

A frequência de pulsação do arame é proporcional à velocidade de rotação do disco. Uma luva de alumínio auxilia o deslocamento do conduíte, para evitar travamentos. Além disto, o conduíte fica engastado no lado que recebe o arame do alimentador (junta de apoio) e se desloca em uma junta prismática no lado que direciona o arame para a tocha. Isso permite que o conduíte se desloque/deslize no eixo horizontal dentro da junta prismática, reduzindo assim os esforços para a deformação do mesmo. A junta prismática em seu lado oposto também permite o acoplamento do conduíte que direcionará o arame para a tocha, garantindo assim o alinhamento do arame nesta transição.

\subsubsection{Avaliação da potencialidade do dispositivo com acionamento eletromecânico para influenciar o desempenho do processo TIG}

Foi realizado um levantamento inicial dos parâmetros do dispositivo, sendo possível atingir frequências na faixa de 19 a $44 \mathrm{~Hz}$ e amplitudes na faixa de 8 a $17 \mathrm{~mm}$ durante para a pulsação do arame [15]. Na sequência foi avaliado seu funcionamento em operação de soldagem. Para esta avaliação, foi utilizado o processo TIG com soldagem de simples deposição sobre chapa com um arame de aço inoxidável (1,2 mm de diâmetro - classe AWS ER 308LSi) como metal de adição e chapas de aço comum ao carbono como placas de teste ( $3 \mathrm{~mm}$ de espessura). Chama-se atenção de que o uso de aço inoxidável sobre aço carbono visou, além da simulação de revestimento (aplicação típica para esta abordagem), facilitar a metalografia pelo contraste entre estes dois metais.

A placa de teste foi posicionada sobre uma mesa de deslocamento com controle de velocidade linear, ficando a tocha TIG e a respectiva alimentação de arame, estacionárias (em uma posição fixa). As soldagens foram realizadas com o uso de uma fonte eletrônica comercial de soldagem, que trabalha no modo corrente constante. O mesmo valor de corrente de soldagem foi regulado para todos os experimentos. A alimentação de arame foi conseguida pelo uso de um alimentador comercial de arame para soldagem TIG. A entrada do arame na poça (sob a ação do arco) se deu à frente da mesma, com o arame entrando alinhado à direção de soldagem em um ângulo de aproximadamente $45 \circ$ em relação à placa de teste. Não foi utilizado sistema AVC (Arc Voltage Control) para manter comprimento de arco constante, pois, por se basear na tensão, poderia levar a arcos com comprimento diferentes ao se fazer comparações. Os parâmetros de soldagem utilizados são mostrados na Tabela 1. Vale ressaltar que aqui, diferentemente do comum às técnicas TIPTIG e TIGSpeed, o arame não foi aquecido antes de entrar na poça, ou seja, foram avaliadas as técnicas com e sem pulsação com alimentação de arame frio.

Tabela 1. Parâmetros regulados para as soldagens para avaliação do efeito da pulsação de alimentação de arame sobre o processo TIG (eletrodo = tungstênio com 2\% de tório, 2,4 mm diâmetro e ângulo de afiação 30; Gás de proteção = Argônio puro a $10 \mathrm{l} / \mathrm{min})$.

\begin{tabular}{lcc}
\hline \multicolumn{1}{c}{ Parâmetro } & $\begin{array}{c}\text { TIG com alimentação pulsada } \\
\text { de arame }\end{array}$ & $\begin{array}{c}\text { TIG com alimentação contínua } \\
\text { de arame }\end{array}$ \\
Corrente de soldagem $(\mathrm{A})$ & 160 & 160 \\
Distância eletrodo peça $(\mathrm{mm})$ & 5 & 5 \\
Velocidade de Soldagem $(\mathrm{cm} / \mathrm{min})$ & 20 & 20 \\
Velocidade de alimentação de arame $(\mathrm{m} / \mathrm{min})$ & 0,7 & 0,7 \\
Amplitude nominal de pulsação do arame $(\mathrm{mm})$ & 8 & 0 \\
Frequência nominal de pulsação do arame $(\mathrm{Hz})$ & 15 & 0 \\
\hline
\end{tabular}


Os sinais de tensão e corrente foram adquiridos por um sistema A/D, a uma frequência de $5 \mathrm{kHz}$. Como meio de análise do movimento, usou-se uma câmera de alta velocidade em conjunto com uma fonte de LASER infravermelho próximo [16]. Também foi utilizado na frente da câmera um Filtro Óptico Comar 905IH25. Com o uso da fonte de LASER (95 W de potência) se pode iluminar a região de interesse e ao realizar filmagens com o devido filtro (deixando passar apenas o espectro de luz do lazer) na câmera de alta velocidade, elimina-se o espectro de luz visível, inclusive o brilho/luz do arco. Verificou-se pelos vídeos a formação de uma gota na ponta do arame no intervalo de tempo em que a ponta do arame não toca a poça, mesmo com a alimentação contínua (a velocidade de alimentação não era tão alta para a energia do arco).

\subsubsection{Resultados e discussão}

Pelos oscilogramas de tensão e corrente obtidos da soldagem TIG com alimentação pulsada de arame (Figura 3a) e alimentação contínua (Figura 3b), nota-se que a fonte de soldagem operou no modo de corrente constante a um nível de aproximadamente $160 \mathrm{~A}$ em ambos casos. Curiosamente, a ação do pulsador levou a uma variação de tensão do arco em intervalos regulares (Figura 3a), a uma frequência de $15 \mathrm{~Hz}$, variando sua amplitude em uma faixa aproximada de 11,7 a 12,3 V. No patamar superior da tensão, o arame ainda não tocou a poça de fusão e a gota está em formação. Já em alimentação contínua (Figura 3b) a variação da tensão foi em intervalos irregulares, variando sua amplitude em uma faixa aproximada de 11,8 a 12,8 V. Este pequeno aumento de tensão nos patamares superiores para quando da alimentação contínua está relacionado ao não enterramento do arame na poça antes da transferência (alterando a impedância do sistema).
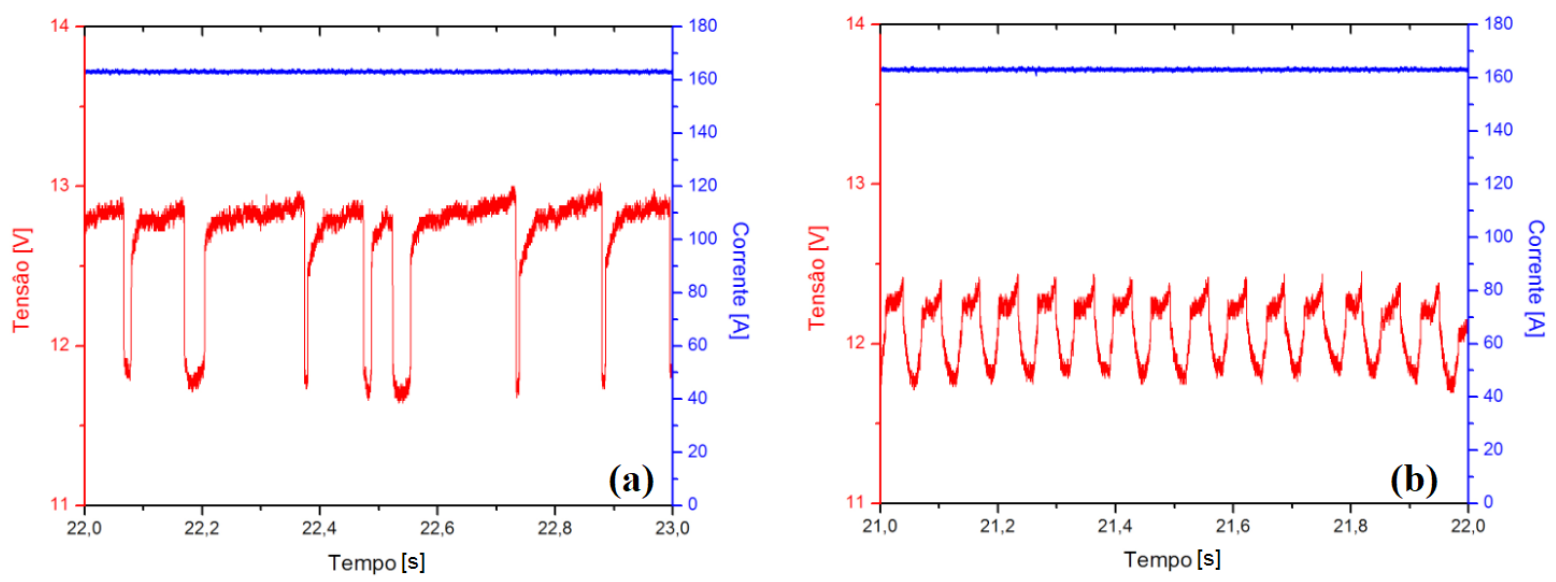

Figura 3. Oscilogramas de tensão e corrente monitorados para processo de soldagem TIG: (a) com alimentação pulsada de arame; (b) com alimentação contínua de arame.

A transferência se dá por tensão superficial e a tensão do arco é reduzida (patamar inferior), como ilustra a Figura 4. A regularidade dos oscilogramas sugere também uma homogeneidade no volume da gota formada na ponta do arame e transferida para a poça, durante o avanço e recuo da ponta do arame. Observando agora os oscilogramas de tensão e corrente no caso da alimentação contínua, nota-se também uma variação da tensão em dois patamares ao longo do tempo, como no caso da pulsação da alimentação. Porém, os valores e a diferença de amplitude da tensão no caso da alimentação contínua foram maiores e os períodos irregulares. Isto sugere uma inconstância também no volume das gotas em transferência para a poça (ora gotas grandes são transferidas, ora gotas menores são transferidas), como ilustra a Figura 5.

Para melhor ilustrar o ganho de regularidade de transferência de gotas do metal de adição obtida na soldagem TIG com alimentação pulsada de arame, a Figura 6, com base em intervalos de tempo de 1 segundo (Figura 3), apresenta resultados de medição dos tempos de formação das gotas na ponta do arame (no patamar de tensão superior) e de transferência para a poça de fusão (no patamar de tensão inferior), como indicado nas sequências 


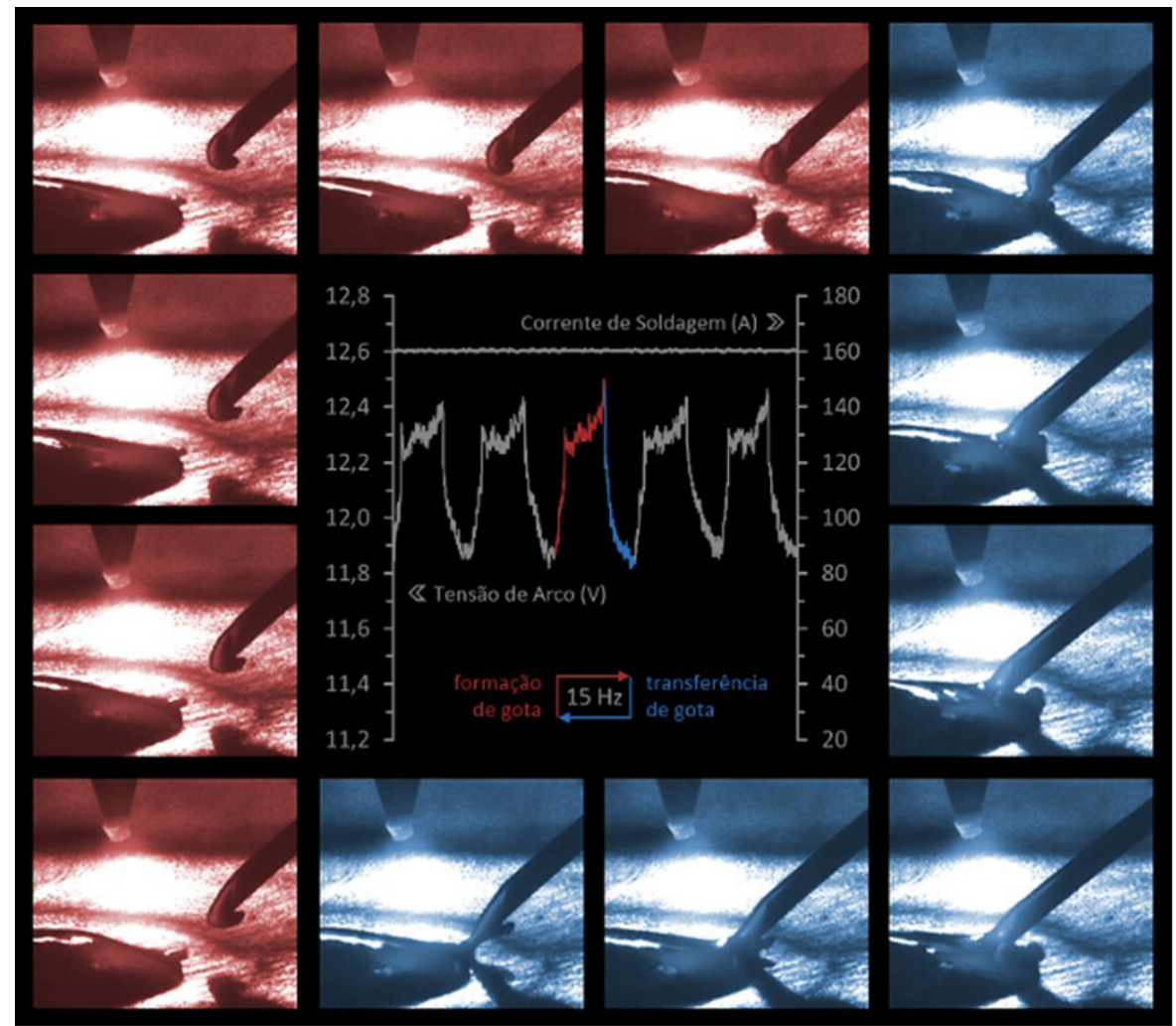

Figura 4. Sequência (em sentido horário) de imagens da formação e transferência das gotas para o processo de soldagem TIG com alimentação pulsada de arame (imagem de capa da revista Soldagem \& Inspeção, Vol. 21, № 4, Out/Dez, 2016 - imagens colorizadas digitalmente).

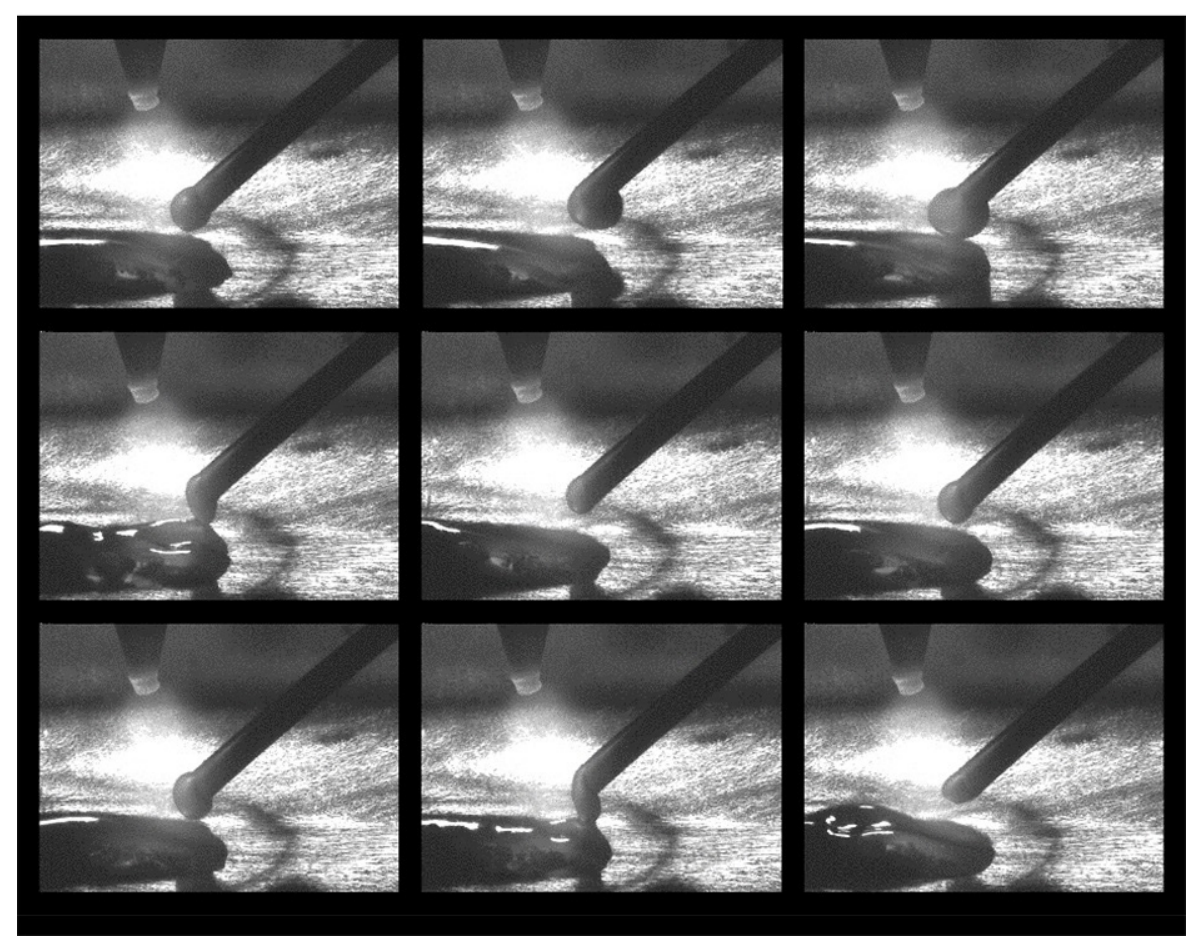

Figura 5. Sequência (da esquerda para a direita e de cima para baixo) de imagens da formação e transferência das gotas para o processo de soldagem TIG com alimentação contínua de arame. 


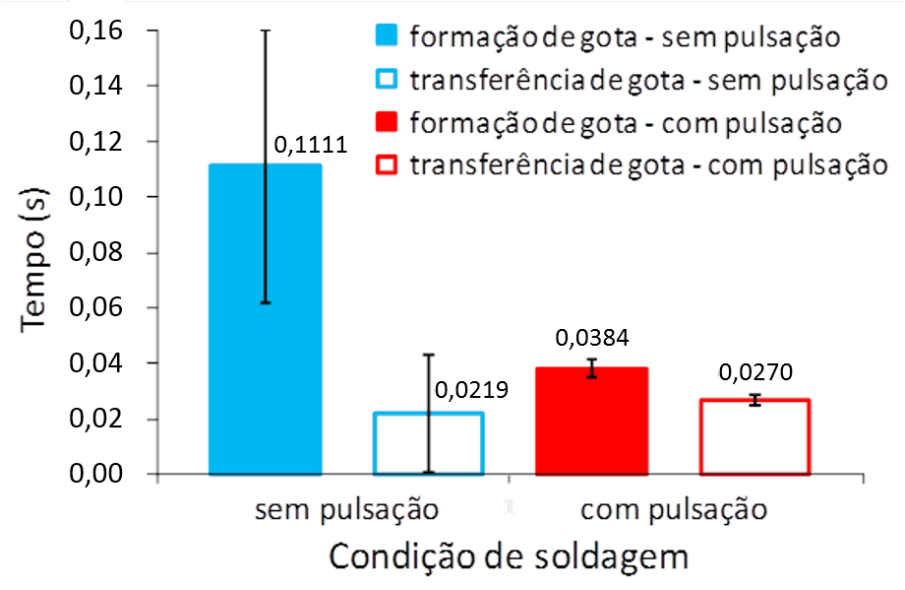

Figura 6. Tempos de formação das gotas na ponta do arame e de transferência para a poça de fusão com e sem pulsação da alimentação de arame.

de imagens das Figuras 4 e 5 . Em relação à queda de tensão entre os patamares, uma hipótese seria haver um circuito paralelo no arco, isto é, eletrodo-poça e eletrodo-ponta do arame-poça. Assim, sempre que a corrente não precisar mais também passar pela ponta do arame (como acontece quando o arame está contato com a poça, ou seja, a impedância do circuito eletrodo-ponta do arame-poça torna-se nula), a tensão torna-se menor. Nota-se que o desvio padrão dos tempos medidos no caso sem pulsação é significativamente maior do que o obtido no caso com pulsação. Isso mostra como a formação da gota, principalmente, e sua transferência para a poça de fusão (que se dá ao tocá-la) parecem depender da ação do próprio movimento da poça. Já no caso com pulsação, as gotas são formadas e transferidas em tempos determinados pela posição da ponta do arame, a qual é imposta pelo pulsador desenvolvido. Em relação à duração média dos tempos, parece que a ação da poça de sorver as gotas da ponta do arame por tensão superficial não foi alterada pela ação mecânica do pulsador ao recuar o arame. O tempo de formação da gota não é governado pelo avanço do arame, mas sim pela frequência da imposição da flexão do arame e pelo tempo que a ponta do arame permanece sob ação do arco elétrico.

Para revelação macrográfica do perfil de fusão dos cordões, os cordões produzidos com e sem pulsação da alimentação de arame foram cortados em uma seção (próxima ao meio do comprimento do cordão), com posterior lixamento até 600 mesh e ataque com reagente Nital 10\% (Figura 7). Os parâmetros geométricos do perfil de fusão foram medidos com auxílio de software comercial de tratamento de imagem (ImageJ). O aspecto superficial dos cordões produzidos foi similar. Entretanto, pelas secções transversais, nota-se claramente que a geometria do perfil do cordão se diferenciou bastante em alguns aspectos, com destaque para a penetração, profunda e concentrada ao utilizar a pulsação da alimentação de arame e rasa e distribuída sem o uso da pulsação. No caso com pulsação da alimentação de arame, a penetração máxima deve ter ficado deslocada lateralmente devido ao fato do arame não ter entrado bem alinhado à direção de soldagem (isso deve ser alvo de verificação em testes futuros). A possibilidade de sopro magnético foi descartada devido as placas de testes terem a mesma dimensão e posicionadas de forma similar sobre uma mesa, não havendo caminho preferencial de corrente. As diferenças em penetração podem ser, hipoteticamente, devidas ao fato de que o arame, ao entrar e sair rapidamente da poça a $15 \mathrm{~Hz}$, agite a massa fundida. Assim, essa agitação modificaria o perfil de convecção de calor dentro da poça, resultando na mudança de perfil de fusão com penetração profunda e concentrada. Porém, esta explicação carece de confirmação, inclusive de outras fontes bibliográficas. Até por que Silva et al. [6] e Silwal e Santangelo [4] não encontraram variação de penetração em comparações similares. Entretanto, Silva et al. [6] trabalharam com frequência menor do que 2 Hz, enquanto Silwal e Santangelo [4], mesmo em frequência similar, não operam com o arame tocando a poça de fusão antes da transferência.

A utilização da pulsação da alimentação de arame propiciou um ganho de penetração de mais de $40 \%$. Esse ganho de penetração chama a atenção até pelo fato de que a potência de soldagem com pulsação ter sido cerca de $100 \mathrm{~W}$ menor do que quando comparado à alimentação contínua. Percebe-se também um cordão com 

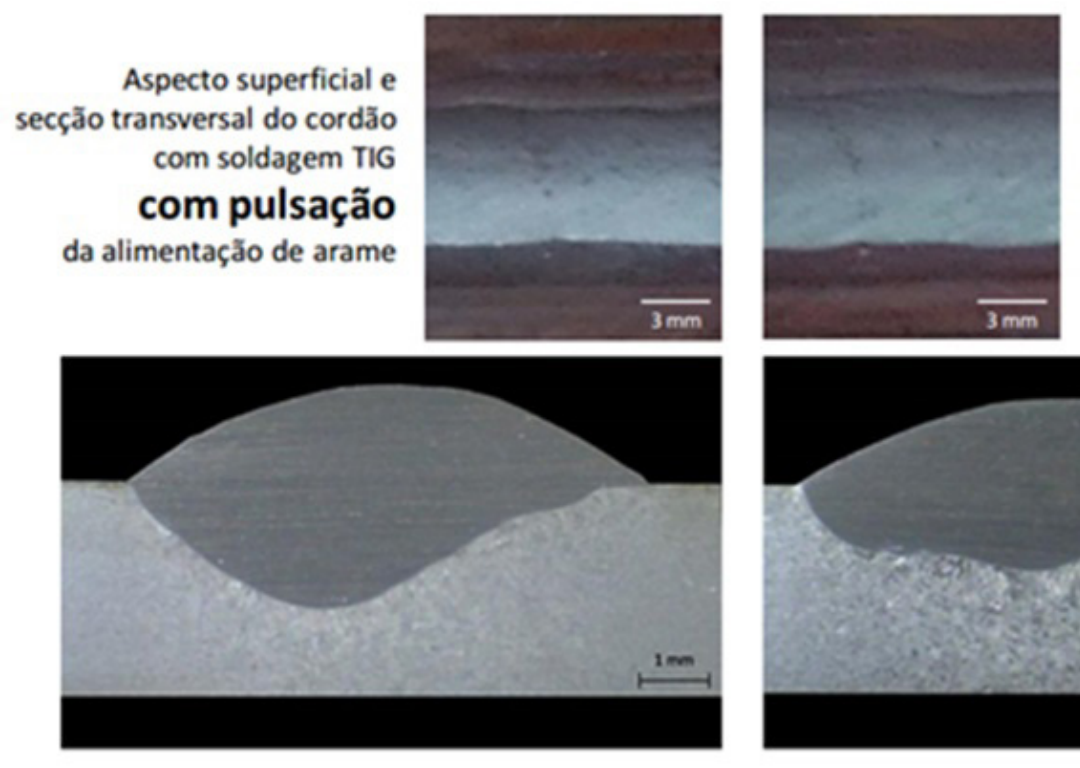

Aspecto superficial e seç̧ão transversal do cordão com soldagem TIG sem pulsação da alimentação de arame

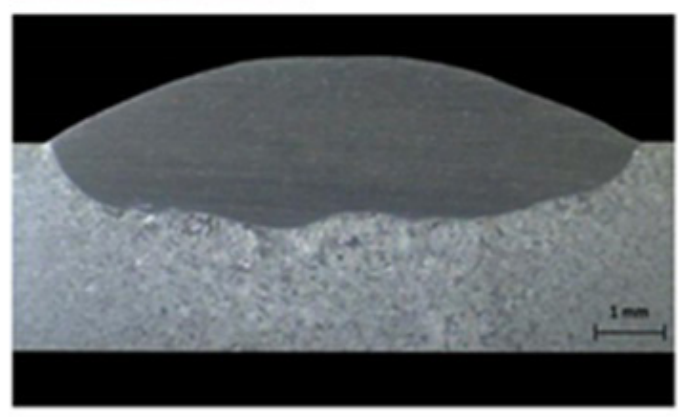

Figura 7. Aspecto superficial e secções transversais dos cordões de solda.

menor largura e mais convexo para o caso da pulsação. Neste caso, a maior convexidade no modo de alimentação pulsada deve estar relacionada a um arco menor (menor tensão), mesmo com a mesma corrente de soldagem. A menor potência (para uma mesma velocidade de soldagem, como foi o caso) leva a um menor aquecimento do metal de base e assim menos molhamento e espalhamento (maior altura do reforço) do cordão de solda.

\subsection{Dispositivo com acionamento eletromagnético}

\subsubsection{Funcionamento}

O dispositivo para acionamento eletromagnético mostrado na Figura $2 \mathrm{~b}$ foi desenvolvido a partir do princípio de repulsão e atração entre o campo magnético de solenoides e imãs permanentes. No centro dos solenoides, um eixo deslizante é responsável por impor um movimento transversal (flexão) ao conduíte. Este eixo é constituído por dois tarugos cilíndricos de ferro fundido nodular (usinados com tolerância deslizante em termos de diâmetro). Cada cilindro é colocado no interior de um solenoide. Nas suas extremidades, são colocados imãs permanentes. Por serem os cilindros de material altamente ferromagnético, eles têm a função de concentrar as linhas de campo geradas pelo solenoide, aumentando a interação dos campos magnéticos com os dos imãs permanentes. Desta forma, a resultante das interações magnéticas entre os dois propulsores (solenoides e imãs permanentes) se somam, aumentando a ação da força transversal resultante sobre o conduíte. Quando o conduíte é flexionado pela ação do eixo deslizante, consequentemente o arame que está passando em seu interior também sofre alteração no curso, recuando em relação à linha de referência, resultando em uma determinada amplitude de pulsação longitudinal da alimentação do arame na saída.

\subsubsection{Avaliação da potencialidade do dispositivo com acionamento eletromagnético para influenciar o desempenho do processo MIG/MAG}

Foram realizadas soldagens de simples deposição sobre placas de teste de aço inoxidável, confeccionadas a partir de barras chatas com dimensões de $160 \times 28 \times 6 \mathrm{~mm}$. Foi usado arame maciço da classe AWS ER70S-6, com diâmetro $1,0 \mathrm{~mm}$ e a proteção do arco foi feita com uma mistura Argônio- $25 \% \mathrm{CO}_{2}$ com vazão regulada em $14 \mathrm{l} / \mathrm{min}$. A soldagem foi realizada com o uso de uma fonte eletrônica de soldagem comercial, trabalhando no modo tensão constante. Esta configuração permitiu a regulagem da tensão e velocidade de alimentação do arame. Os sinais de tensão e corrente foram adquiridos por um sistema A/D a uma frequência de $5 \mathrm{kHz}$. O movimento da tocha foi realizado por um robô de 6 eixos. Também não foi utilizado sistema AVC (Arc Voltage Control). Os parâmetros de soldagem utilizados são mostrados na Tabela 2, típicos para se atingir uma transferência do tipo globular. Este 
Tabela 2. Parâmetros regulados para as soldagens para avaliação do efeito da pulsação de alimentação de arame sobre o processo MIG/MAG.

\begin{tabular}{ccccccc}
\hline Testes & $\begin{array}{c}\text { Amplitude } \\
\text { nominal de } \\
\text { pulsação } \\
\text { do arame } \\
\text { (mm) }\end{array}$ & $\begin{array}{c}\text { Frequência de } \\
\text { nominal de } \\
\text { pulsação } \\
\text { do arame } \\
\text { (Hz) }\end{array}$ & $\begin{array}{c}\text { Vsold } \\
\text { (cm/min) }\end{array}$ & $\begin{array}{c}\text { DBCP } \\
\text { (mm) }\end{array}$ & $\begin{array}{c}\text { Tensão } \\
\text { (V) }\end{array}$ & $\begin{array}{c}\text { Valim } \\
\text { (m/min) }\end{array}$ \\
*Teste 1-A & 0 & 0 & 20 & 19 & 34 & 4,8 \\
*Teste 1-B & 6 & 16 & 20 & 19 & 34 & 4,8 \\
Teste 2 & 4 & 16 & 20 & 19 & 34 & 4,8 \\
Teste 3 & 2 & 16 & 20 & 19 & 34 & 4,8 \\
Teste 4 & 4 & 26 & 20 & 19 & 34 & 4,8 \\
Teste 5 & 4 & 20 & 20 & 19 & 34 & 4,8 \\
\hline
\end{tabular}

*Soldagens feitas habilitando a pulsação a partir da metade do comprimento do cordão em mesma placa de teste.

modo de transferência metálica foi escolhido visando maior sensibilidade para se detectar o efeito da pulsação do arame sobre o desempenho do processo, quantificado pelos sinais da corrente e tensão transitórias no domínio do tempo (oscilogramas). Chama-se atenção que esta não é uma condição para aplicação típica do processo, já que as aplicações serão estudadas de forma mais sistemáticas e divulgadas oportunamente. É importante ressaltar que não foi utilizado nenhum controle realimentado para sincronização entre a pulsação mecânica do arame e sinais de corrente e tensão da fonte de soldagem.

\subsubsection{Resultados e discussão}

Analisando os oscilogramas de corrente e tensão do Teste 1 (Figura 8), nota-se um intervalo (de 0 a 11 s) de oscilação transiente dos sinais de forma caótica quando a pulsação da velocidade de arame não é aplicada. Chama-se atenção para o fato de que, ao se trabalhar com a fonte tensão constante, o processo tenta corrigir
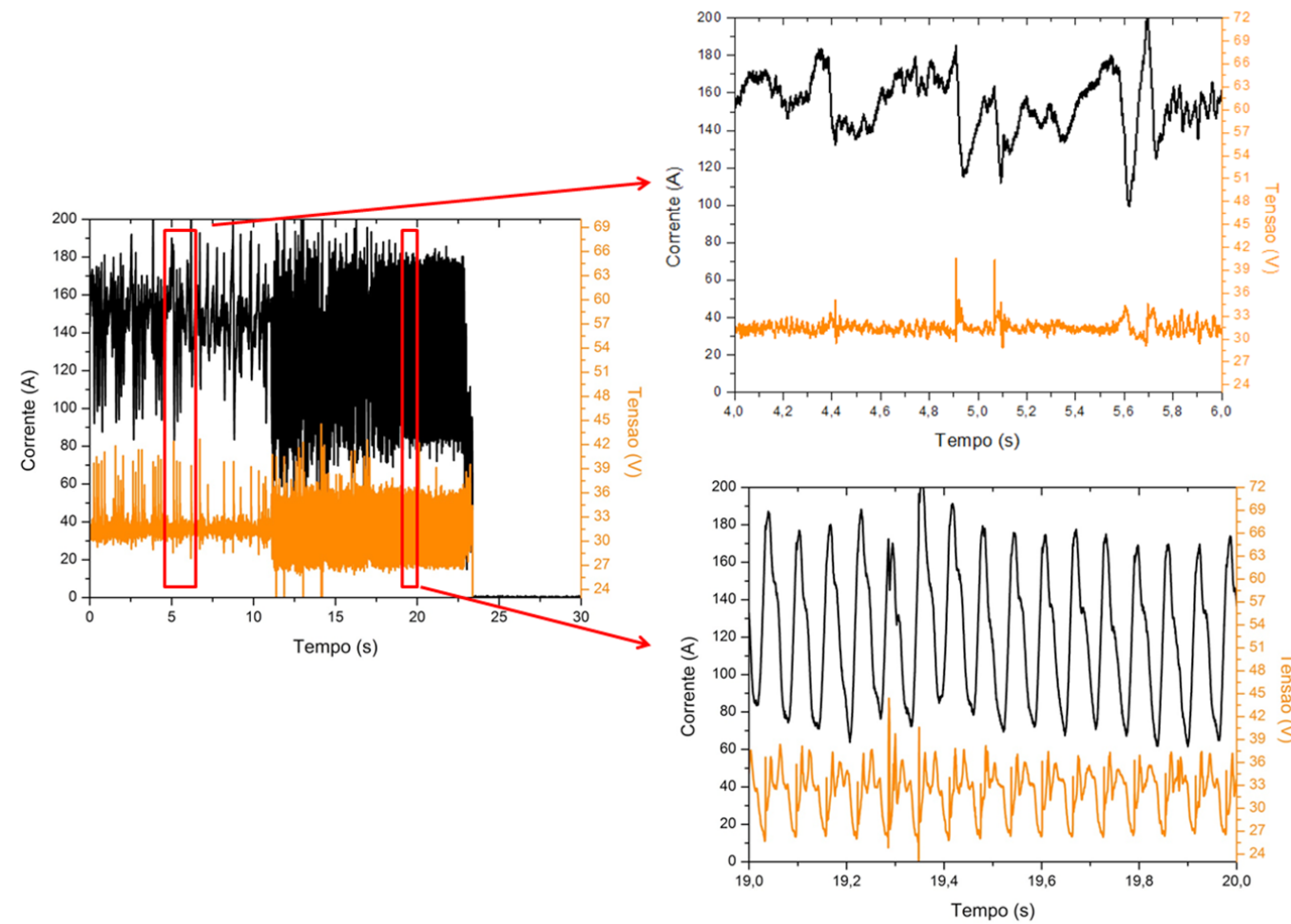

Figura 8. Oscilogramas de corrente e tensão monitorados para o Teste 1-A (0 a 11 s) e Teste 1-B (11 a 23 s). 
automaticamente o comprimento do arco. No caso de transferência globular, mesmo sem a pulsação da alimentação do arame há variação do comprimento do arco, que se torna mais curto à medida que a gota cresce (o arco fica acoplado sob a gota em formação), mudando-se para o valor máximo repentinamente ao destacar a gota. Este fenômeno é caracterizado pelos valores dinâmicos do sinal de corrente (a corrente cresce para arcos mais curtos e decresce para arcos mais longos), que é livre quando se usa a fonte no modo tensão constante (a variação de amplitude da tensão observada no oscilograma quando a oscilação da velocidade de alimentação não é habilitada reflete principalmente ruídos dos sinais, de alta frequência).

Já quando se habilitou a pulsação da velocidade de alimentação do arame, a partir do intervalo de 11 a 23 segundos da Figura 5, os oscilogramas passam a ser regulares, acompanhando o movimento dinâmico da pulsação. Quando o arame é puxado, a fonte também tenta corrigir automaticamente a altura do arco, que neste caso, ficou maior. Assim o efeito ativo da corrente atua, diminuindo-a. Quando o arame é empurrado, o arco diminui (reduzindo a tensão) e a corrente aumenta. É possível perceber que o pico da corrente está sempre sincronizado com o vale da tensão, assim como os menores valores de corrente estão sempre sincronizados com os picos de tensão. Estes efeitos são reproduzidos ciclicamente na mesma frequência da pulsação da alimentação.

Apesar de ter sido verificado o efeito da pulsação sobre o comportamento da transferência metálica pela Figura 8, testes complementares foram aplicados para se conhecer o efeito da amplitude e frequência de pulsação (Tabela 2). Quando se manteve a frequência constante e variou-se a amplitude de pulsação da alimentação de arame (testes 1-B, 2 e 3 da Tabela 2), é interessante apontar que se reduziu as distâncias ente vales e picos da tensão com a diminuição da amplitude de pulsação, mas pouca alteração se nota em relação à corrente. A Figura 9 ilustra esta situação comparando o Testes 1-B (6 mm de amplitude de pulsação) e o Teste 2 (4 mm de amplitude de pulsação). Quando se manteve a amplitude constante e variou-se a frequência de pulsação da velocidade de arame (testes 2, 4 e 5 da Tabela 2), foi possível perceber que os oscilogramas de tensão e corrente se comportam de forma similar ao apresentado na Figura 9, apresentando oscilações periódicas na mesma frequência de pulsação da velocidade do arame.
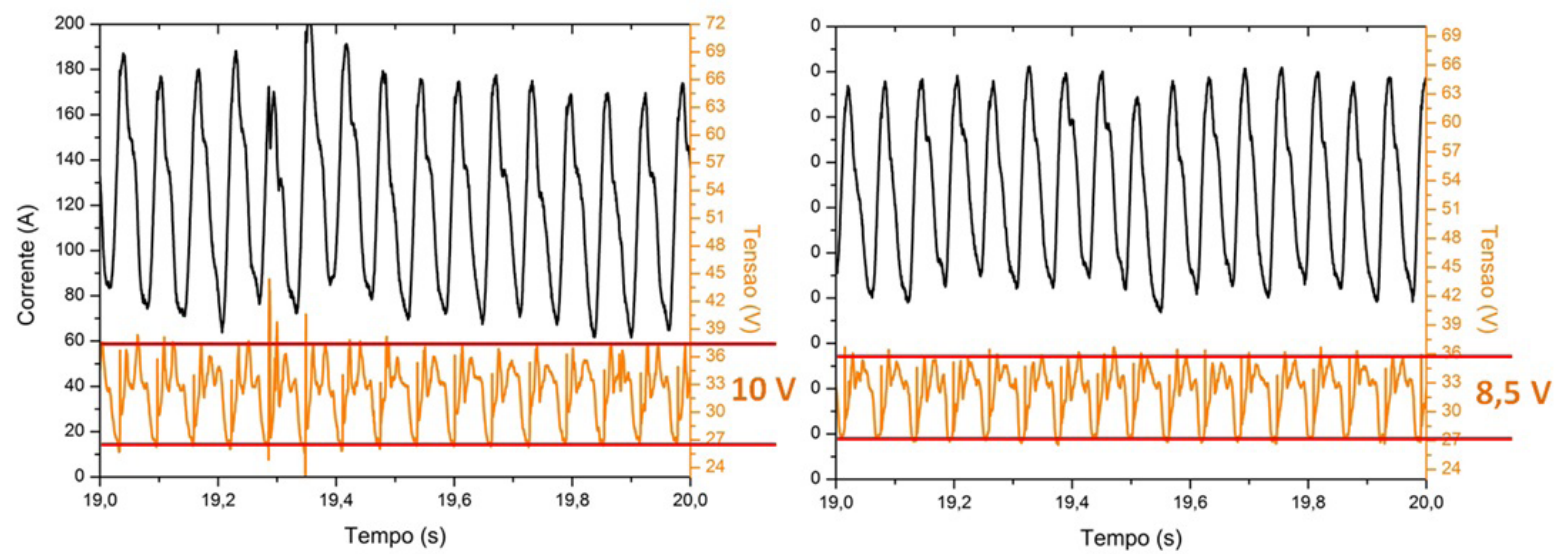

Figura 9. Oscilogramas de corrente e tensão monitorados para o Teste 1-B (à esquerda) e Teste 2 (à direita).

Os valores médios e eficazes de corrente e tensão para os testes executados são mostrados na Tabela 3. Ao comparar os valores médios e eficazes de corrente do teste referência (Teste 1-A) e dos testes utilizando pulsação do arame (Teste 1-B ao Teste 5), nota-se uma redução das correntes médias e eficazes. Isto quer dizer que, para uma mesma velocidade de alimentação, a pulsação do arame consegue manter a mesma taxa de fusão com menores valores de corrente, evidenciando mais uma vez o efeito da pulsação da velocidade de alimentação do arame sobre o desempenho do processo. É importante apontar que se a taxa de fusão é a mesma a uma corrente maior, o comprimento livre do arame-eletrodo tornou-se maior para manter o balanço da equação geral 
de consumo [17]. Assim, o comprimento de arco com alimentação pulsada é menor. Esta característica pode ser utilizada no futuro para desenvolver métodos alternativos para o processo MIG/MAG.

Finalmente, a Tabela 4 apresenta as caraterísticas geométricas (valores de largura, penetração e altura do reforço) dos cordões realizados com a parametrização mostrada na Tabela 2. Pela Tabela 4 e Figura 10, a pulsação do arame reduziu a largura do cordão de solda em torno de $2 \mathrm{~mm}$ e aumentou a altura do reforço em torno de $0,5 \mathrm{~mm}$, quando comparado ao cordão do Teste 1-A (sem pulsação). Nota-se também que a pulsação concentrou a penetração no centro do cordão para todos os casos, independentemente da frequência ou amplitude utilizadas,

Tabela 3. Valores de corrente (I) e tensão (U) médias e eficazes monitorados para os testes da Tabela 2.

\begin{tabular}{ccccc}
\hline Testes & Imed (A) & Irms (A) & Umed (V) & Urms (V) \\
Teste1-A & 145,7 & 146,8 & 31,5 & 31,6 \\
Teste1-B & 123,7 & 130,2 & 32,1 & 32,3 \\
Teste2 & 126,5 & 131,5 & 32 & 32,1 \\
Teste3 & 129,6 & 133,7 & 31,9 & 32 \\
Teste4 & 129,8 & 132,3 & 32 & 32,1 \\
Teste5 & 128,7 & 132 & 32 & 32,1 \\
\hline
\end{tabular}

Tabela 4. Valores mensurados de largura, penetração e altura do reforço para os cordões de solda resultantes dos testes da Tabela 2.

\begin{tabular}{cccc}
\hline \multirow{3}{*}{ Teste } & \multicolumn{3}{c}{ Dimensões dos cordões } \\
\cline { 2 - 4 } & Largura $(\mathbf{m m})$ & Penetração $(\mathbf{m m})$ & Altura do Reforço $(\mathbf{m m})$ \\
1 1-A & 10,34 & 1,06 & 1,81 \\
$1-B$ & 8,39 & 1,02 & 2,35 \\
2 & 8,48 & 1,13 & 2,32 \\
3 & 8,78 & 1,02 & 2,04 \\
4 & 8,29 & 1,12 & 2,15 \\
5 & 8,35 & 1,27 & 2,32 \\
\hline
\end{tabular}
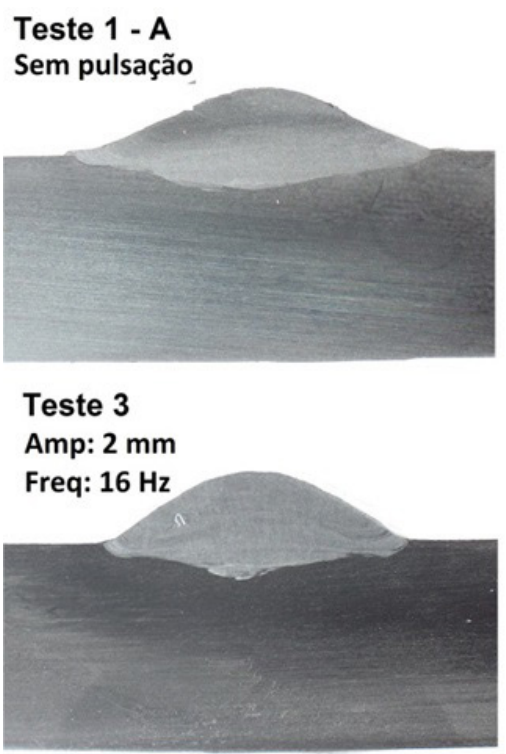
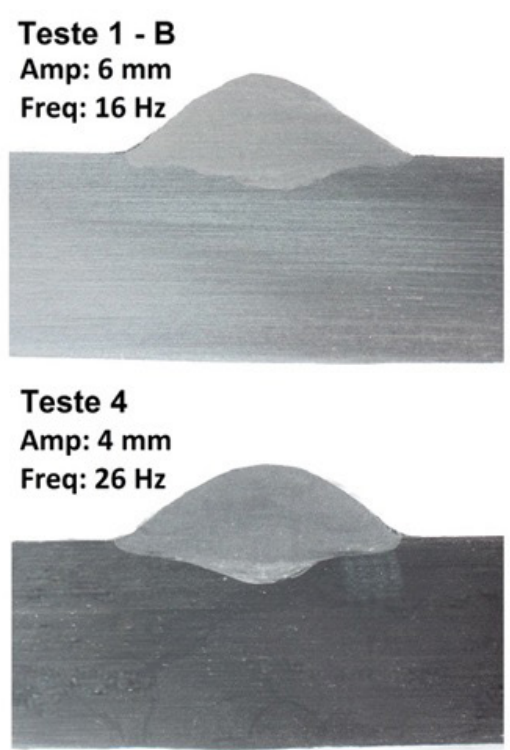

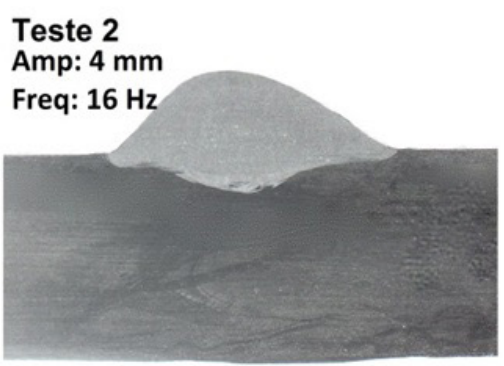

Teste 5

Amp: $4 \mathrm{~mm}$

Freq: $20 \mathrm{~Hz}$

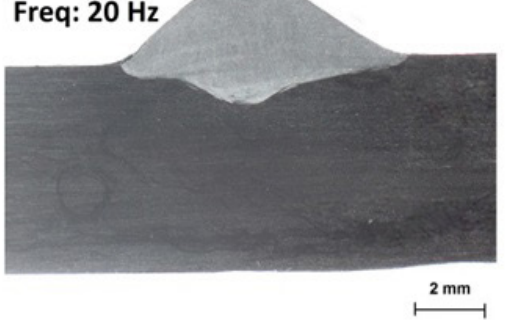

Figura 10. Aspectos geométricos dos cordões de solda resultantes dos testes conforme Tabela 2. 
modificando a forma do cordão de solda. Estes fenômenos poderiam ser explicados por um menor comprimento de arco, o que confirmaria a hipótese do aumento do comprimento livre do arame-eletrodo quando se aplica pulsação da velocidade de alimentação do arame. Um menor comprimento induz o arco a ser mais concentrado e com menor distribuição de calor pelas laterais do cordão em formação.

\section{Conclusão}

Atendendo o objetivo exploratório do trabalho, as duas técnicas utilizadas demonstraram potencial para pulsar a alimentação do arame, tanto no TIG e como no MIG/MAG, de forma controlada, com configuração externa ao cabeçote e não utilizando tochas especiais externa aos alimentadores. Ambos sistemas, eletromecânico e eletromagnético, permitem a regulagem de uma ampla faixa de frequência e de amplitude de avanço-recuo da ponta do arame. Embora estes valores sejam maiores para o sistema eletromecânico, o sistema eletromagnético tem a vantagem de ser mais flexível quando à regulagem em tempo real. É importante dizer que estas características podem ser alteradas pelo aperfeiçoamento do projeto de ambos sistemas, fato que foge do escopo do presente trabalho.

Conclui-se também, de forma exploratória, mas original, que a pulsação da alimentação de arame, tanto no processo TIG quanto no processo MIG/MAG, é capaz de interferir no processo, abrindo um campo de estudo e desenvolvimento de tecnologias derivativas em soldagem. De um modo geral, a pulsação da velocidade de alimentação fez, nas condições testadas, aumentar a penetração, mas também a convexidade dos cordões. É importante ressaltar que estas características podem ser investigadas para otimização, fato que também foge do escopo do presente trabalho.

\section{Agradecimentos}

Os autores agradecem à CAPES, ao CNPq e à FAPEMIG, pelos apoios financeiros em bolsas, consumíveis e projeto de pesquisa para desenvolvimento do projeto, e aos membros e colaboradores do Laprosolda/UFU (Grupo Centro para Pesquisa e Desenvolvimento de Processos de Soldagem), pela ajuda durante a montagem dos dispositivos e execução dos testes.

\section{Referências}

[1] Rudy JF. Development and application of dabber gas tungsten arc welding for repair of aircraft engine, seal teeth. In: Proceedings of ASME Turbo Expo: Power for Land, Sea, and Air; 1982 April 18-22; London, England. Vol. 2. London: ASME; 1982. Paper No. 82-GT-55.

[2] Plasch S. Device for feeding a welding wire to a welding device USA. United States patent US 2016/0059342. 2016.

[3] Pike G. Evaluation of the tip tig welding system, a semiautomatic hot wire GTAW process. Newport News: Newport News Shipbuilding; 2013.

[4] Silwal B, Santangelo M. Effect of vibration and hot-wire gas tungsten $\operatorname{arc}$ (GTA) on the geometric shape. Journal of Materials Processing Technology. 2018;251:138-145. http://dx.doi. org/10.1016/j.jmatprotec.2017.08.010.

[5] Santangelo M, Silwal B, Purdy A. Vibration assisted robotic hot-wire gas tungsten arc welding (GTAW) for additive manufacturing of large metallic parts. In: Solid Freeform Fabrication 2016: Proceedings of the 26th Annual International Solid Freeform Fabrication Symposium: An Additive Manufacturing Conference; 2016; Austin, USA. Austin: University of Texas; 2016.

[6] Silva RHG, Paes LES, Okuyama MP, Sousa GL, Viviani AB, Cirino LM, et al. TIG welding process with dynamic feeding: a characterization approach. International Journal of Advanced Manufacturing Technology. 2018;96(9-12):4467-4475. http:// dx.doi.org/10.1007/s00170-018-1929-6.
[7] Fronius International GMBH. CMT: Cold Metal Transfer. Alemanha: Welds; 2014 [acesso em 1 maio 2018]. Disponível em: https:// www3.fronius.com/cps/rde/xbcr/SID-2A1C35D8-F51D9A1F/ fronius_brasil/CMT_cold_metal_transfer_pt.pdf

[8] Paton Electroweld Ind. Electromagnetic appts for pulsed feeding of welding wire: contains set of elastic washers differing in stiffness, connected to intermediate pushers, as return unit. SU 1107-977-A. 1983 May 20.

[9] Paton Electroweld Ind. Appts for pulsed feeding of welding wire: has pressing unit in form of collared bushings between which are mounted clamping globules in contact with conical walls. SU 1472-197-A. 1987 Sept 27.

[10] Karpov GG. Appts for pulsed feed of electrode wire: contains packs of slotted springs as pushing and arresting clamps mounted in movable core and stationary nozzle respectively. SU 1127-719-A. 1983 Sept 22.

[11] Paton Electroweld Ind. Appts for pulsed feeding of welding wire: contains two one-way grips sepd. by revolving with opening eccentrically located in relation to grips. SU 6465-24. 1977 Feb 21.

[12] Paton Electroweld Ind. Appts for pulsed feeding of electrode wire: contains at least two pairs of gripping units mounted in separators with peg contacting inclined guided slots in casing. SU 1433-677-A. 1987 Jan 5.

[13] Paton Electroweld Ind. Clamp for pulsed feeding of welding wire: has hollow shaft with flanges pushing two rollers having 
Desenvolvimento e Avaliação de Técnicas para Pulsação da Alimentação de Arame em Soldagem a Arco

necks in inclined slots in movable casing. SU 1337-214-A. 1986 Mar 11.

[14] Gribachev MV. Appts for supplying filler wire: contains mechanism changing step of movement in form of two kinematically connected clutches of free-wheeling type. SU 1634-416-A. 1989 Feb 7.

[15] Santos CHA. Desenvolvimento de um protótipo para pulsação da alimentação de arame na soldagem TIG [monografia]. Uberlândia: Universidade Federal de Uberlândia; 2016.
[16] Mota CP, Machado MVR, Finzi RM No, Vilarinho LO. Sistema de visão por infravermelho próximo para monitoramento de processos de soldagem a arco. Soldagem e Inspeção. 2013;18(1):19-30. http://dx.doi.org/10.1590/S0104-92242013000100004.

[17] Silva DCC, Scotti A. Using either mean or RMS values to represent current in modeling of arc welding bead geometries. Journal of Materials Processing Technology. 2017;240:382-387. http:// dx.doi.org/10.1016/j.jmatprotec.2016.10.008. 